\section{Carcinoma Diferenciado da Tiróide (Papilífero e Folicular): Diagnóstico e Conduta}

\section{DIAGNÓSTICO}

$\mathrm{O}$ CÁncer de tiróide é a neOrlasia endócrina mais comum; sua incidência, entretanto, é pequena e estimada, nos EUA, em 30 a 60 casos novos por milhão de habitantes por ano (1-5). Esta incidência vem aumentando, relacionada ao diagnóstico mais precoce e, recentemente, em muitos lugares da Europa, ao grande número de pacientes com carcinoma papilífero conseqüente à exposição radioativa na área de Chernobyl (6).

Os tumores da tiróide são habitualmente classificados de acordo com os critérios da Organização Mundial de Saúde cm epiteliais, nãoepiteliais, miscelâneos, metástases de outros tumores e lesões pseudotumorais, quase todos podendo ser benignos e malignos (7) (tabela 1).

Tabela 1. Classificação simplificada dos tumores da tiróide.

\begin{tabular}{ll}
\hline Benignos & Malignos \\
\hline 1. Bócio endêmico & 1. Carcinoma folicular \\
2. Bócio esporádico & 2. Carcinoma papilífero \\
3. Adenoma folicular & 3. Carcinoma medular \\
4. Outros & 4. Carcinoma indiferenciado \\
& 5. Outros \\
\hline
\end{tabular}

Entre os tumores benignos são mais comuns o bócio endêmico c o esporádico, considerados lesões pseudo-tumorais. A deficiência de iodo na alimentação é a maior causa do bócio endêmico, que guarda a distribuição geográfica equivalente às áreas iodoprivas. Estima-se que cerca de $200 \mathrm{mi}-$ thões de pessoas em todo o mundo têm a tiróide aumentada por esta causa. Os demais tumores benignos da tiróide são denominados adenomas. São raros, de origem epitelial, bem encapsulados, não invadem os tecidos vizinhos e não produzem metástases.

Os tumores malignos da tiróide são raros e apresentam quadros clínicos extremamente variáveis, desde aqueles com crescimento muito lento e compatíveis com a expectativa de vida normal, até aqueles com péssima evolução e que levam ao óbito em períodos de semanas ou meses. Têm como origem 3 tipos diferentes de células, as folicularcs, as para-foliculares $\mathrm{c}$ as de origem não-tiroidiana. As foliculares, que constituem a quase totalidade dos elementos celulares da tiróide, são responsáveis por cerca de $90 \%$ ou mais dos carcinomas tiroidianos. Os tumores deste tipo mostram diferenciação histológica bastante evidente entre os carcinomas bem diferenciados e os indiferenciados. Os diferenciados, que são a maioria absoluta dos derivados das células foliculares (mais de 90\%), são subdivididos em dois grupos, os papilíferos e os foliculares. Os indiferenciados ou anaplásicos constituem apenas $5 \%$ dos carcinomas tiroidianos. As células para-foliculares, produtoras de calcitonina, são responsáveis por cerca de $5 \%$ dos carcinomas tiroidianos, os medulares. As células de origem não-tiroidiana causam diversos tumores malignos da tiróide, que não ultrapassam a taxa de

\section{artigo original}

\author{
Rui M.B. Maciel
}

Recebido em $01 / 7 / 98$

Revisado em $24 / 7 / 98$ Aceito em $28 / 7 / 98$ 
$5 \%$ do total. Entre eles se destacam os linfomas da tiróide, os cárcino-sarcomas, as lesões metastáticas, os teratomas e os hemangioendoteliomas (7).

$\mathrm{O}$ câncer de tiróide apresenta-se geralmente como um nódulo na região cervical; porém, menos do que $5 \%$ dos nódulos de tiróide são canceres e a maior dificuldade do médico é afastar uma neoplasia num nódulo, uma vez que as lesões benignas são a grande maioria das lesões nodulares da tiróide (95\%) (tabela 2) (1-5). Habitualmente a descoberta do nódulo é acidental, pelo médico ou pelo próprio paciente ou sua família; mais raramente, o doente é visto pela primeira vez em virtude da presença de metástases no pescoço, pulmão ou ossos. Os dados de história sugestivos de malignidade são radioterapia prévia na região anterior da cabeça e/ou pescoço ou a existência de casos familiares de câncer de tiróide (1-5).

Tabela 2. Lesões benignas que podem se apresentar como "nódulo".

Adenoma da paratiróide
Adenoma da tiróide
Aneurismas
Bócio multinodular
Broncocele
Cirurgia anterior
Cisto do ducto tiroglosso
Cisto da paratiróide
Cisto da tiróide
Efeito de terapêutica com iodo radioativo
Fibrose local
Hemiagenesia da tiróide
Higroma cístico
Laringocele
Linfonodos
Tiroidite de Hashimoto
Tiroidite sub-aguda

Ao exame físico, os sinais semiológicos que sugerem malignidade são fixação do nódulo às estruturas subjacentes (traquéia e músculos), falta de mobilidade do mesmo à deglutição c extensão da doença aos linfonodos cervicais; alguns consideram a consistência endurecida, ou até pétrea do nódulo, como sinal importante de malignidade, porém, muitas vezes, esta consistência é devida à calcificação de cistos benignos (tabelas 3 e 4) (1-12).

As dosagens dos hormônios TSH e T4 livre não acrescentam muito ao diagnóstico do nódulo de tiróide, pois estão normais na absoluta maioria dos casos; outras vezes, nota-se o nódulo numa glândula com características palpatórias de tiroidite de Hashimoto, como aumento de tamanho e consistência à palpação, num paciente com anticorpos anti-tiroidcanos positivos e até
Tabela 3. Características dos nódulos tiroideanos benignos.

História familiar de bócio benigno

Nódulo de longa duração sem crescimento recente Bócio multinodular

Bócio difuso

Nivel elevado de anticorpos anti-tiroideanos

Nódulo puramente cístico à ultra-sonografia

Nódulo "quente" à cintilografia

Citologia benigna ò CAAF

Tabela 4. Características dos nódulos tiroidianos malignos.

História:

Câncer da tiróide prévio

História familiar de câncer da tiróide

Nódulo em criança menor de 14 anos

Exposição à radioterapia no pescoço e face

Rouquidão

Nódulo de crescimento rápido

Nódulo doloroso

Nódulo recente no sexo masculino

História de metástases à distância

Exame fisico:

Nódulo de consistência pétrea

Nódulo fixo às estruturas vizinhas

Adenopatia cervical

Paralisia de corda vocal

Achados de laboratório:

CAAF positiva para câncer ( $99 \%$ de chance)

CAAF suspeita para câncer $(33 \%$ de chance de carcinoma folicular)

Nódulo "frio" solitário (10-20\% de chance)

Nódulo que avança sobre estruturas extra-tiroidianas ao ultra-som

Calcitonina e CEA elevados em pacientes em risco de câncer medular

quadro clínico de hipotiroidismo, o que indica que a tiroidite de Hashimoto pode se apresentar na forma de um nódulo palpável. A dosagem de calcitonina sérica, basal ou estimulada, é importante para a confirmação de suspeita de carcinoma medular, mas trabalho recente evidenciou que pode estar elevada em nódulos malignos causados por outras formas de carcinoma (13). É importante lembrar que a dosagem de tiroglobulina é o teste principal no seguimento dos pacientes tratados, mas não tem indicação no diagnóstico inicial desses tumores, uma vez que é inespecífica, pois diversas outras doenças também ocasionam o seu aumento $(1,4)$.

O dado mais importante para o diagnóstico do nódulo tiroidiano é a citologia aspirativa com agulha fina (CAAF). É um método seguro, eficiente e relativamente atraumático, utilizado não apenas para afastar câncer, mas para o diagnóstico de diversas doenças tiroidianas, como tiroidite de Hashimoto, bócio colóide, linfoma e cárcinomas papilifero, medular e anaplásico; a dificuldade de diferenciação entre adenoma e carcinoma folicular, pela impossibilidade técnica de se observar invasões de cápsula ou vasos ao exame citológico, não é 
Tabela 5. Achados citológicos mais importantes na CAAF.

\begin{tabular}{|c|c|}
\hline $\begin{array}{l}\text { Bócio colóide } \\
\text { colóide abundante; células foliculares pequenas; } \\
\text { material cístico; macrófagos }\end{array}$ & $\begin{array}{l}\text { Bócio tóxico } \\
\text { pouco colóide; sangue abundante; células foliculares grandes; } \\
\text { vacúolos marginais }\end{array}$ \\
\hline $\begin{array}{l}\text { Carcinoma anaplásico } \\
\text { granulócitos; cêlulas bizarras sem componente } \\
\text { folicular; mitoses frequentes; fragmentos necróticos }\end{array}$ & $\begin{array}{l}\text { Carcinoma papilifero } \\
\text { células foliculares em papilas; inclusões intranucleares; colóide } \\
\text { viscoso: macrófagos }\end{array}$ \\
\hline $\begin{array}{l}\text { Tumor folicular } \\
\text { Grupos de células foliculares de tamanho igual; } \\
\text { pouco colóide; sangue abundante }\end{array}$ & $\begin{array}{l}\text { Tiroidite aguda } \\
\text { granulócitos; necrose; material protéico }\end{array}$ \\
\hline $\begin{array}{l}\text { Tiroidite sub-aguda } \\
\text { células foliculares pequenas; células histiocitárias } \\
\text { gigantes; linfócitos e macrófagos; células epitelióides }\end{array}$ & $\begin{array}{l}\text { Linfoma } \\
\text { grande quantidade de células linfóides monomórficas; núcleos } \\
\text { redondos e uniformes com inclusão citoplasmática }\end{array}$ \\
\hline $\begin{array}{l}\text { Tiroidite crônica } \\
\text { células foliculares grandes e oncociticas; numerosos } \\
\text { linfócitos; raras células histio-citárias gigantes }\end{array}$ & $\begin{array}{l}\text { Carcinoma medular } \\
\text { células parafoliculares em blocos ou isoladas; amilóide; } \\
\text { necrose e células inflamatórias; componentes papilares }\end{array}$ \\
\hline
\end{tabular}

um problema na infância, uma vez que os adenomas incidem em grupos etários mais elevados. As características principais da citologia das doenças da tiróide estão sumarizadas na tabela 5 . Os dados de literatura dos grupos experientes em CAAF demonstram valores de sensibilidade e especificidade superiores a 95\% (1-12).

Os demais exames subsidiários acrescentam pouco ao diagnóstico. A cintilografia com iodo radioativo ou tecnécio, durante muitos anos o principal instrumento para o diagnóstico diferencial dos nódulos, ć hoje suplantada pela CAAF. O cmprego da cintilografia no diagnóstico diferencial dos nódulos foi decorrente da observação de que a maioria dos canceres de tiróide, quando comparados ao tecido normal, não ten a mesma capacidade de acumular e organificar quantidades suficientes de jodo radioativo ou tecnécio; assim, sua aparência é a de um nódulo năo funcionante ou "frio" à cintilografia. Todavia, o contrário, ou seja, a afirmação de que qualquer nódulo "frio" poderia ser um câncer da tiróide, năo é verdadeira, pois a freqüência de câncer nos nódulos "frios" na população como um todo é de apenas 10 a $20 \%$, tendo em vista que uma grande parte dos nódulos "frios" é causada por lesões benignas (cistos, nódulos colóides, adenomas benignos degenerados, cistos da paratiróide e tiroidite de Hashimoto) (tabela 2). Em conseqüiência, nenhum paciente portador de nódulo tiroideano deve ser selecionado para cirtrgia com base apenas no critério da presença de um nódulo "frio". Os nódulos que captam mais iodo que os tecidos vizinhos, denominados nódulos tóxicos ou "quentes", são habitualmente hiperfuncionantes e causadores de hipertiroidismo (doença de Plummer) e raramente malignos; aqueles que captam iodo em concentrações semelhantes às do tecido circundante normal ("mornos") também são habitualmente benignos. Desta maneira, na prática, exceto pelo caso específico do nódulo tóxico, a cintilografia não acrescenta muito ao diagnóstico diferencial dos nódulos e a tendência atual na literatura mundial é omiti-la cada vez mais (1-13).

A ultra-sonografia de tiróide (UST), apesar de proporcionar imagens de alta resolução, ainda tem um papel controverso na avaliação dos nódulos (14). Em nossa opinião deve ser considerada como uma extensão do ato palpatório do médico, devendo ser realizada pelo mesmo. A princípio, a indicação mais comum da UST cra o estudo dos nódulos "frios" à cintilografia, objetivando diferenciar lesões sólidas de císticas, pois as puramente císticas tinham incidência muito baixa de malignidade ( 1 a $2 \%$ ), quando comparadas às sólidas (13 a 32\%) (14). A melhoria técnica dos últimos anos, entretanto, utilizando transdutores mais sensíveis, tem evidenciado que quase nunca os nódulos săo puramente císticos, contendo no seu interior material sólido ou sangue antigo acumulado, atributos do adenoma ou carcinoma folicular on, até mesmo, do carcinoma papilífero; assim, alguns grupos têm demonstrado prevalência de 12 a $33 \%$ de câncer em nódulos císticos. Desta mancira, a simples diferenciação entre sólido e cístico não define o diagnóstico (14). Das várias características sonográficas estudadas em detalhe pela literatura até agora, para a obtenção de 
um possível sinal característico de malignidade (presença de halo ou banda ccóica, componentes císticos, calcificações, hipo ou hetero-ccogenicidade do padrão interno do eco, verificação de borda da lesão irregular ou sem nitidez, tipo de irrigação sangiúnea do nódulo ou da área circunvizinha), apenas a extensão da massa para as regiões extra-tiroidianas é que tem indicado malignidade da lesão (14). Desta mancira, o maior inconveniente da UST é a falta de especificidade; por outro lado, é um exame útil para uma séric de parâmetros da avaliação semiológica, tais como confirmação de nódulo de palpação duvidosa, determinação acurada do volume da tiróide, deteç̧ão precoce de lesões ocultas em pacientes submetidos à irradiaçăo prévia, verificação das características da glândula (doença focal, multifocal ou difusa), do nódulo (sólido, cístico, calcificado), do contorno dos nódulos, acompanhamento da evolução do tamanho de um nódulo em tratamento, guia para CAAF em nódulos de difícil palpação, observação de linfonodos e do leito tiroidiano pós-tiroidectomia e avaliação de tecido tiroidiano ectópico (14). Alén disso, no futuro, o contínuo aperfeiçoamento dos equipamentos deverá proporcionar informaçōes cada vez mais específicas.

Outras técnicas de imagem têm sido testadas no diagnóstico diferencial dos nódulos (tomografia computarizada, ressonância nuclear magnética, cintilografia com tálio-20l ou gálio-67 e termografia), mas nenhuma, até agora, tem sido usada rotineiramente (1-12).

Apesar da semelhança no sintoma principal, ou seja, a presença do nódulo, existem algumas diferenças entre os quadros clínicos dos diferentes tipos de câncer da tiróide (tabela 6). O carcinoma papilífero incide em indivíduos mais jovens, inclusive crianças, e corresponde, nas diversas séries estudadas, a cerca de 40 a $70 \%$ de todos os carcinomas tiroidianos (5-12). Seu crescimento é lento c apresenta baixo grau de malignidade, de modo que períodos longos são necessários para o seu aparecimento. De maneira geral o prognóstico é bom e pelo menos $80 \%$ dos pacientes estão vivos cerca de 10 anos após o diagnóstico. As grandes sćries da literatura indicam que o carcinoma papilífero ć um processo essencialmente benigno nos adultos jovens, raríssimamente levando ao óbito os pacientes abaixo dos 40 anos. Sua disseminação se dá por meio dos linfáticos intra-glandulares, evoluindo do foco inicial para as outras partes da tiróide e para os linfonodos pericapsulares e cervicais; desta maneira, lesões multicêntricas na tiróide são comuns c, por ocasião da apresentação, 25\% dos pacientes tem metástases cervicais, $20 \%$ tem invasăo extra-tiroidiana e $5 \%$ tem metástases à distância, especialmente para o pulmăo. De maneira
Tabela 6. Classificação histológica e comportamento biológico.

\begin{tabular}{|c|c|c|c|}
\hline Tumor & Idade & Crescimento & Metástases \\
\hline Papilífero & Todas & Lento & Linfonodos \\
\hline Folicular & $>40$ & Lento & Distantes \\
\hline Medular & Todas & Moderado & $\begin{array}{l}\text { Linfonodos + dis- } \\
\text { tantes }\end{array}$ \\
\hline $\begin{array}{l}\text { Indiferen- } \\
\text { ciado }\end{array}$ & Idosos & Rápido & Local + distantes \\
\hline
\end{tabular}

curiosa, por razões não completamente esclarccidas, a presença de metástases em linfonodos cervicais não está relacionada, nos jovens, a pior prognóstico. As metástases pulmonares podem ter distribuição miliar ou como imagens numulares. As lesões papilíferas apresentam comumente áreas de padrão papilífero misturadas a areas de padrão folicular, o mesmo ocorrendo com as metástases. Quase todos os canceres papiliferos captam iodo radioativo e, muitas vezes, também produzem hormônios tiroidianos, levando o paciente a desenvolver um quadro de hipertiroidismo. Os $5-10 \%$ dos casos de carcinoma papilífero que evoluem para a morte são constituídos pelo grupo de pacientes acima dos 40 anos que apresentam lesões aderentes às estruturas vizinhas ou com metástases invasivas cervicais ou à distância (5-12).

O carcinoma folicular ocorre num grupo etário mais avançado do que o papilífero, tendo seu pico de incidência por ocasião da 5 a. década da vida, mas também é 3 vezes mais freqüente nas mulheres. Corresponde a cerca de 20 a $40 \%$ de todos os carcinomas tireoidcanos. Da mesma mancira que o papilífero, o carcinoma folicular é diagnosticado pela presença de nódulo único na tiróide. Outras vezes, porém, apresenta-se como um crescimento recente num bócio de longa duração ou por uma metástase à distância. Em cerca de 15 a $20 \%$ dos casos o diagnóstico é realizado pela história de metástase à distância, como fraturas patológicas ou múltiplos nódulos no pulmão e ossos. Também diferentemente do câncer papilífero, o folicular raramente mostra metástases cervicais. Muito raramente pode surgir um caso de hipertiroidismo ocasionado pelo excesso de produção de iodotironinas pelas metástases. Apesar de não existirem estudos tão sistemáticos dos fatores prognósticos no carcinoma folicular, a maioria dos autores considera que a idade é o mais importante aspecto, com evolução muito melhor aqueles pacientes cuja moléstia se iniciou abaixo dos 40 anos. O outro fator importante é a invasividade do tumor, pois aqueles com alto grau de invasão dos vasos e da cápsula, têm pior prognóstico. Finalmente, a presença de metástases ao diagnóstico está também associada a uma pior evolução (5-12). 


\section{CONDUTA}

Diante de tantos testes, o médico pode ficar confuso na condução de um caso de nódulo da tiróide; outras vezes, para aumentar a dificuldade, o paciente já traz consigo uma série de exames, à primeira vista contraditórios entre si e quer uma decisão. A conduta por nós empregada no diagnóstico de um nódulo da tiróide é semelhante à descrita em vários textos atuais (1-12) e se baseia na CAAF, que tem se tomado, à medida que o tempo passa, o teste inicial na maioria dos serviços com experiência no manuscio do nódulo da tiróide. Como já dito anteriormente, as dosagens de T4 livre e TSH ultra-sensível, além da medida dos anticorpos antitiroidianos devem ser requisitadas, apesar de que estão normais na maioria dos casos; entretanto, utilizando estes testes pode-se detectar casos de hipertiroidismo devido a nódulo tóxico ou hipotiroidismo secundário à tiroidite de Hashimoto de forma nodular. A cintilografia ainda tem indicação quando se suspeita de nódulo "quente". Na figura l esquematizamos nossa conduta na avaliação do nódulo de tiróide.

O tratamento do câncer da tiróide inclui, de modo geral, cirurgia, seguida da ablação do tecido remanescente ou metástases diferenciadas com ${ }^{131}$ I e terapêtutica substitutiva com T4 (5-12). A cxtensão da cirurgia necessária para o tratamento continua sendo um assunto controverso na literatura, $\mathrm{em}$ virtude da variedade de comportamento biológico dos diversos tipos de tumores e das complicações dependentes de cirurgias mais radicais. A terapêtutica com l31 I é possível graças à capacidade da célula tiroidiana e de suas metástases diferenciadas de captar iodo; o isótopo pode ser bastante benéfico no tratamento de metástases inacessíveis à cirurgia, sem provocar lesões ras estruturas vizinhas. Todavia, não existe consenso entre os autores sobrc o papel do ${ }^{131}$ I na ablação do tecido

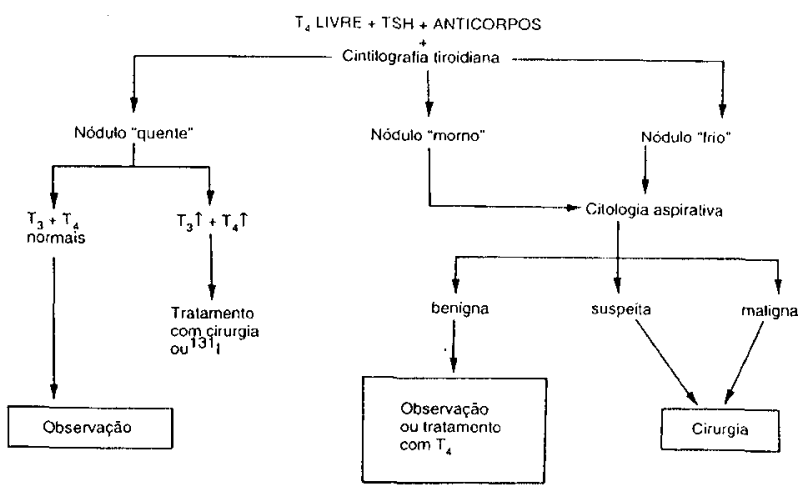

Figura 1. Fluxograma diagnóstico do nódulo tiroideano. remanescente no leito tiroidiano após a tiroidectomia. Os tumores diferenciados são dependentes do TSH para o seu crescimento; desta maneira, é importante a terapêutica substitutiva com T4, não apenas para promover o cutiroidismo dos doentes, mas também para bloquear o TSH endógeno. Apesar dessas normas gerais de tratamento serem as mesmas para todos os tipos de câncer tiroidiano, existem algumas diferenças dependentes da histologia e do estadiamento.

O procedimento de escolha para o tratamento cirúrgico do carcinoma papilífero de diâmetro inferior a $1,5 \mathrm{~cm}$ pode ser a lobectomia do mesmo lado do tumor, associada à istmectomia (tiroidectomia sub-total, TST) ou a tiroidectomia total ou quase total (TT ou TQT). A razão da primeira conduta está relacionada à benignidade deste tipo de tumor e aos riscos dos efeitos colatcrais da cirurgia, tais como hipoparatiroidismo e lesão dos nervos recorrentes; a TST torna as complicações menos prováveis e aumenta muito a chance de remoção total do tumor. Na TST o istmo deve ser removido porque, na eventualidade de restar algo do câncer na região adjacente à traquéia, esta pode ser invadida pelo tumor; em conseqüência, a resseç̧ão total do mesmo fica praticamente impossível sem a remoção da traquéia. $\mathrm{Se}$ o tumor tiver um diâmetro maior do que $1,5 \mathrm{~cm}$, entretanto, nossa conduta privilegia a tiroidectomia total (TT) ou quase total (TQT), que consiste na retirada total da glândula sem danificar as paratiróides ou os nervos recorrentes; estas estruturas são identificadas cuidadosamente, mas quase sempre uma pequena parte da tiróide é conservada quando o cirurgião percebe algum risco na TT, especialmente na cápsula posterior no lado contra-lateral ao tumor. Nesta conduta acompanhamos divcrsos cirurgiões de renome, tanto nacionais, como internacionais. Outros serviços, entretanto, indicam a TST, quer porque os estudos prospectivos a longo prazo não demonstraram que a TT é superior à TST, quer porque o risco das complicações da TT ultrapassa os benefícios potenciais da retirada total da glândula, especialmente quando o cirurgião não é um especialista em cabeça e pescoço. Estes autores citam estudos retrospectivos de várias séries cirúrgicas onde ocorrem complicações em até $29 \%$ dos casos por ocasião da TT. Por outro lado, cirurgiões bem treinados apresentam em suas estatísticas uma incidência de hipoparatiroidismo menor do que $2 \%$. Além disso, 20 a $80 \%$ dos tumores papiliferos são multicêntricos; é claro que nem todos estes focos serão de importância clínica, mas é importante citar que $10 \%$ dos doentes apresentam recorrência do tumor no lobo contra-lateral e $50 \%$ desses pacientes morrem do câncer de tiróide. Desta mancira, devido à multicentricidade, à ocorrência de 
óbitos quando não se faz a TT e a habilidade de cirurgiōes especialistas em evitar o hipoparatiroidismo por ocasião da TT, preferimos nesses casos uma ressecção mais extensa. A TT ou TQT deve ser associada sempre com a inspeção direta dos linfonodos regionais e excisão daqueles nódulos com crescimento metastático suspcito ou evidente; se houver comprometimento extenso dos linfonodos, indica-se a dissecção "modificada" do pescoço (5-12).

A terapêutica ablativa com iodo radioativo influencia de maneira significativa o tratamento do câncer papilífero, diminuindo a recorrência e o resultado final. A indicação do tratamento radioterápico é a presença de captação residual no leito tiroidiano, especialmente se a lesão primária tiver tido um diâmetro maior do que $1,5 \mathrm{~cm}$, metástases cervicais ou invasão local. A dose média empregada pela lite-

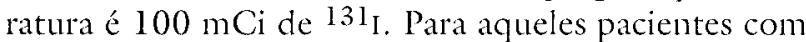
tumores cuja lesão primária tiver tido um diâmetro menor do que $1,5 \mathrm{~cm}$, não há a necessidade do iodo radioativo. Muito importante também é a terapêutica supressiva com tiroxina, uma vez que o carcinoma papilífero é dependente de TSH. O paciente deve começar com uma dose única diária de 0,15 mg de Ltiroxina e medir o TSH cerca de 4 semanas depois; se esta dosagem suprimir o TSH, deve ser mantida; se não, recomenda-se elevá-la até $0,2 \mathrm{mg}$ ao dia. Um bom tempo da consulta deve ser utilizado para convencer o paciente da necessidade de manter a aderência rígida à medicação (5-12).

Como o carcinoma folicular da tiróide é mais agressivo que o papilífero, deve ser tratado de forma mais agressiva. O procedimento cirúrgico de cscolha para o tratamento do carcinoma folicular com invasão de cápsula ou de vasos é a TT ou a TQT. Mesmo naquelas ocasiões onde o diagnóstico é definido apenas pela parafina, alguns dias depois da cirurgia, indica-se a TT. No carcinoma folicular a maioria dos autores recomenda a ablação actínica com ${ }^{131}$ I para a destruição total de massa tiroidiana remanescente no leito cervical. O procedimento nestas circunstâncias consta da realização da pesquisa de corpo inteiro (PCI), 4 a 6 semanas depois da cirurgia, com o paciente em hipotiroidismo, utilizando-se 3 a $5 \mathrm{mCi}$ de ${ }^{131}$ I como dose traçadora. Este procedimento deverá se modificar brevemente, tendo em vista a futura disponibilidade do TSH humano recombinante, o que permitirá a realização da pesquisa de corpo inteiro sem a necessidade do estado de hipotiroidismo (16). Se houver captação suficiente na região cervical, realiza-se ablação com dose terapêutica do iodo radioativo, utilizando-se doses médias de $100 \mathrm{mCi}$ de ${ }^{131} \mathrm{I}$. Se entretanto, houver angio-invasão mínima e a captação pós-cirúrgica for muito baixa, não indicamos o iodo radioativo. Apesar do prognóstico pior nos doentes com metástases por ocasião do diagnóstico, o tratamento dessas lesões distantes tem produzido bons resultados, com os indivíduos tratados tendo sobrevida maior. A dose adequada para essa terapêutica deve depender da experiência do radioisotopista, levando-se em consideração sempre os limites sugeridos e as técnicas de proteção radiológica para o meio-ambiente. Da mesma maneira que o câncer papilífero, o tratamento com tiroxina nas mesmas bases descritas, é essencial (5-12).

O seguimento clássico dos pacientes com câncer diferenciado da tiróide era feito através do exame clínico periódico, acompanhado da pesquisa, no corpo inteiro, de captação do ${ }^{131} \mathrm{I}$ ( $\mathrm{PCl}$ ), assim como de radiografias ósseas e do tórax quando uma área suspeita é identificada. Este tipo de procedimento, especialmente a $\mathrm{PCI}$, é desagradável para os doentes, pois é necessária a suspensão da terapêutica com tiroxina para a realização do teste, com o subseqüente hipotireoidismo transitório. Além disso, a dose de iodo radioativo recebida em cada PCI é elevada e sua realização periódica no correr dos anos implica numa alta exposição à radiação. A mensuração dos níveis de tiroglobulina ( $\mathrm{Tg}$ ) com os pacientes em uso da tiroxina revelou-se, porém, numa grande série de trabalhos, um ótimo meio diagnóstico para separar os indivíduos com metástases. Assim, todos os pacientes livres de metástases apresentam valores de Tg quase que completamente suprimidos, enquanto que os portadores de metástases evidenciam altos níveis de tiroglobulina e tem supressão parcial. Além dessa vantagem, o procedimento ć mais conveniente para os doentes com boa evolução (a maioria), uma vez que não precisam suspender a tiroxina. A dosagem de Tg também tem se revelado mais sen-

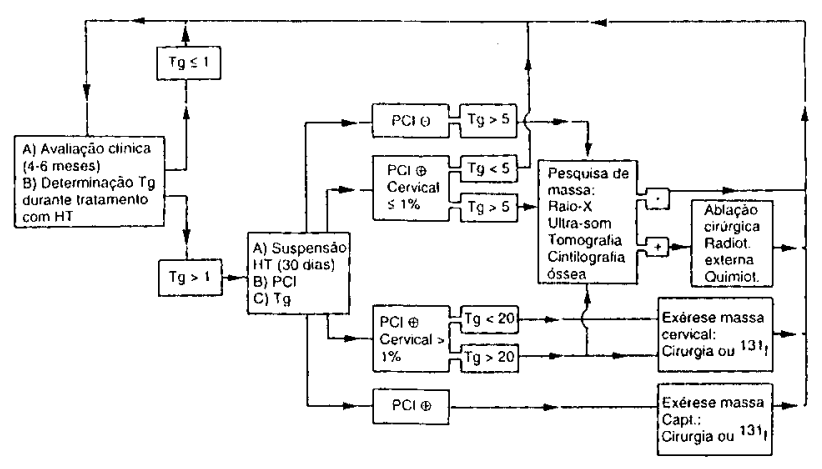

Figura 2. Estratégia de seguimento em pacientes portadores de câncer diferenciado da tiróide após o tratamento. Os niveis de tiroglobulina $(\mathrm{Tg}$ ) estão em $\mathrm{ng} / \mathrm{mL}$. HT = hormônios tiroideanos: $\mathrm{PCl}=$ pesquisa de corpo inteiro com iodo radioativo. 
sivel que a PCI na experiência da maioria dos autores. Desta maneira, a conduta esquematizada na figura 2 é a estratégia de seguimento dos doentes com câncer diferenciado da tiróide após o tratamento (5-12).

\section{REFERÊNCIAS}

1. Schlumberger MJ. Papillary and follicular thyroid carcinoma. N Engl J Med 1998;338:297-306.

2. Singer PA, Cooper DS, Daniels $\mathrm{GH}$ ef al. Treatment guidelines for patients with thyroid nodules and well-differentiated thyroid cancer. Arch Int Med 1996; 156:2165-72.

3. Gharib $H$. Changing concepts in the diagnosis and management of thyroid nodules. Endocrinol Metab Clin North Am 1997;26:777-800.

4. Maciel RMB. Câncer da tiróide. In BL Wajchenberg, Tratado de Endocrinologia Clínica, Editora Roca, São Paulo, 1992:404-27

5. Solomon BL, Wartofsky L, Burman KD. Current trends in the management of well differentiated pappilary thyroid cancer. J Clin Endocrinol Melab 1996;81:333-9.

6. Nikiforov $Y$, Gnepp DR, Fagin JA. Thyroid lesions in children and adolescents after Chernobyl disaster: implications for the study of radiation tumorigenesis. J Clin Endocrinol Metab 1996;81:9-14.

7. Hedinger $C$, Williams ED. Sobin LH. The WHO histological classification of thyroid tumors: a commentary on the second edition. Cancer 1989;63:908-10.

8. Ridgway EC. Clinical evaluation of solitary thyroid nodules. In LE Braverman e RD Utiger, Werner and Ingbar's The Thyroid: a fundamental and clinical text, 7th. edition. Lippincott-Raven. Philadelphia, 1996:966-72.
9. Mazzaferri EL. Management of a solitary thyroid nodule N Engl J Med 1993;328:553-9.

10. Hung $W$. Well diferentiated carcinoma in children and adolescents: a review. The Endocrinologist 1994;4:117-20.

11. Larsen PR, Davies TF, Hay ID. The thyroid gland, In JD Wilson. DW Foster, HM Kronenberg e PR Larsen. Williams Textbook of Endocrinology, 9th, edition, WB Saunders, Philadelphia, 1992:389-515.

12. De Groot LJ. Thyroid neoplasia. In LJ DeGroot, Endocrinology, 3rd. edition, WB Saunders, Philadelphia, 1995:834-54.

13. Routine measurements of plasma calcitonin in nodular thyroid diseases. Vierhapper $\mathrm{H}$, Raber W, Bieglmayer $\mathrm{C}$. Kaserer K. Weinhausl A. Niederle B. J Clin Endocrinol Metab 1997;82:1589-93.

14. Advances in thyroid imaging: thyroid sonography when and how should it be used? M Blum, J Yee. Thyroid Today 1997; XX:1-13.

16. Comparison of administration of recombinant human thyrotropin with withdrawal of thyroid hormone for radioactive iodine scanning in patients with thyroid carcinoma. Ladenson PW, Braverman LE, Mazzaferri EL et al. N Engl J Med 1997;337:888-96.

\section{Endereço para correspondência:}

Rui M.B. Maciel

Disciplina de Endocrinologia, Departamento de Medicina Escola Paulista de Medicina. Universidade Federal de São Paulo

Caixa Postal 20266

04034-970 São Paulo, SP.

e-mail: rmacieł@endocrino.epm.br 